\title{
Camping, weather, and disasters: Extending the Construal Level Theory
}

Christopher Craig

Murray State University, ccraig8@murraystate.edu

\section{Siyao Ma}

University of Arkansas, Fayetteville, siyaoma@uark.edu

Ismail Karabas

Murray State University, ikarabas@murraystate.edu

\section{Song Feng}

University of Arkansas, Fayetteville, songfeng@uark.edu

Follow this and additional works at: https://digitalcommons.murraystate.edu/faculty

Part of the Business Administration, Management, and Operations Commons, Cognitive Psychology Commons, Environmental Studies Commons, and the Tourism and Travel Commons

\section{Recommended Citation}

Craig, C. A., Ma, S., Karabas, I., \& Feng, S. (2021). Camping, weather, and disasters: Extending the Construal Level Theory. Journal of Hospitality and Tourism Management, 49, 353-363.

This Journal Article is brought to you for free and open access by the Faculty Works at Murray State's Digital Commons. It has been accepted for inclusion in Faculty \& Staff Research and Creative Activity by an authorized administrator of Murray State's Digital Commons. For more information, please contact msu.digitalcommons@murraystate.edu. 


\title{
Camping, Weather, and Disasters: Extending the Construal Level Theory
}

\begin{abstract}
:
Camping is an outdoor accommodation and type of recreation that is susceptible to weather and climate change. Camping - in addition to the relationships camping shares with weatherremains understudied despite the subsectors' salient economic impact and high participation rate. The observable effects of non-meteorological/climatological (e.g., pandemic) is also a topic that has received limited attention. Accordingly, we introduce the Camping-Weather-Disaster (CWD) framework to examine the concurrent impact of weather and the COVID-19 disaster on postdisaster camping trip plans among leisure travelers in the 48 contiguous United States $(n=2,442)$. Extending the Construal Level Theory, the CWD framework considers traveler construal (i.e., understanding) of a disaster and psychological distance (i.e., mental frame of reference) from a disaster alongside empirically observable state-level weather and COVID-19 cases. Results demonstrate that (1) concrete construal about timing and distance of travel is positively related to post-disaster camping trip plans; (2) weather is a significant predictor of post-disaster camping trip plans where there are regionally fewer COVID-19 cases; and (3) state-level COVID-19 cases are the most salient predictor of post-disaster camping trip plans where there are regionally more COVID-19 cases. Although the study context is camping, the CWD framework can be applied to other subsectors of tourism to build understanding and adaptive capacity to future natural conditions and disasters.
\end{abstract}

Keywords: construal level theory; camping; coronavirus; climate change; camping climate index (CCI); weather

\section{Cite as:}

Craig, C.A., Ma, S., Karabas, I., \& Feng, S. (2021). Camping, weather, and disasters: Extending the construal level theory. Journal of Hospitality and Tourism Management, 49, 353-363. 


\section{Camping, Weather, and Disasters: Extending the Construal Level Theory}

\section{1. Introduction}

Tourism is among the most exposed industries to the effects of climate change including

4 shifting weather patterns and extreme weather events (Reidmiller et al., 2018; UNWTO, 2019).

5 Comparably, the COVID-19 pandemic has been the most economically impactful disaster

6 tourism has ever experienced (Dolnicar \& Zare, 2020). COVID-19 is a disease caused by the

7 novel SARS-CoV-2 coronavirus (World Health Organization [WHO], 2021), and the global

8 reach of the disease signifies a pandemic. The adverse effects of COVID-19 resulted in an

9 approximately $70 \%$ decline in the global tourism industry from 2019 to 2020 (UNWTO, 2020).

10 Like weather and climate change, COVID-19 has not impacted all tourism subsectors

11 equally (e.g., Gossling et al., 2020; Rutty \& Scott, 2010). For instance, Ma et al. (2021a) report

12 that climate change improved weather for camping across much of the United States from 1984

13 to 2019. Concerning COVID-19, researchers and practitioners alike reported that nature-based

14 tourism and recreation (e.g., camping) rebounded quickly compared to traditional forms of

15 hospitality (e.g., hotels, dining) where permissible into the summer and fall 2020 meteorological

16 seasons (CCG, 2020a; Craig \& Karabas, 2021; Gossling et al., 2020; Kim \& Lee, 2020; Yu et al.,

17 2021; Rice et al., 2020). For example, in response to COVID-19, 59\% and 41\% of campers and

18 non-campers in the United States, respectively, viewed camping as a safe form of travel (CCG,

19 2020a, p. 4). For comparison, far fewer campers and non-campers viewed large hotel (16\% and

$2015 \%$, respectively), small hotel (16\% and 10\%, respectively), and Airbnb accommodations (20\%

21 and $18 \%$, respectively) as safe forms of travel.

22 Camping interactions with its external environment differ from other types of hospitality

23 (CCG, 2020a; Ma et al., 2021b), though to-date the variable effects of weather and non- 
1 meteorological/climatological disasters have not been empirically and concurrently investigated.

2 To address this knowledge gap, we introduce the Camping-Weather-Disaster (CWD) framework

3 to investigate the variable effects of weather and COVID-19 on post-disaster camping trip plans

4 among travelers in the 48 contiguous United States $(n=2,442)$. The CWD extends the Construal

5 Level Theory (CLT; Trope \& Liberman, 2010) by empirically investigating relationships that

6 weather, a disaster (i.e., COVID-19), traveler construal (i.e., understanding) of a disaster, and

7 traveler psychological distance (i.e., mental reference point) from a disaster share with a post-

8 disaster tourism decision (i.e., camping trips where COVID-19 conditions permit).

9 Unfortunately, early projections that the tourism industry would not recover from

10 COVID-19 until 2023 (STR and Tourism Economics, 2020) may still hold due in part to (1)

11 COVID-19 variants accelerating faster than vaccination deployment (Pancevski et al., 2021) and

12 (2) opposition to vaccination (i.e., "anti-vax"; Sear et al., 2020). Vaccination is the

13 administration of a vaccine, which trains "your immune system to create antibodies, just as it

14 does when it's exposed to a disease" (WHO, 2020, par I) like COVID-19. Regardless the

15 duration of the adverse impacts of COVID-19, like previous disasters (e.g., extreme weather

16 [Mahn et al., 2020; Robbie, 2008], terrorist attacks [Arana \& Leon, 2008; Floyd et al., 2008], and

17 epidemics [van Lendt et al., 2017]), COVID-19 provides a fertile research landscape to theorize

18 about and empirically investigate disaster response broadly among leisure travelers.

In support of our empirical analysis, we begin by reviewing select literature pertaining to

20 camping, weather, climate, and disasters, introduce the CWD framework, and present our

21 hypotheses. The remainder of the article consists of methods and measures, results and analysis,

22 theory advancement, and conclusion sections. 
$1 \quad$ 1.1 Camping, Weather, and Climate

Camping provides a useful context to study travel decisions because it is susceptible to

3 factors in the natural environment (e.g., weather, climate), has a high participation rate among

4 United States households, and contributes over \$150 USD billion annually to the United States

5 economy (CCG, 2019; Craig \& Karabas, 2021; Rice et al., 2019). Characteristics of the 2018

6 United States camping year include: (1) a new peak of 78.8 million camping households, (2)

7 demand growth for new camping accommodation options (e.g., glamping, shared RV economy),

8 and (3) an increase in nearby camping trips (CCG, 2019). Comparable to other alternative

9 accommodations (e.g., Airbnb), camping is also becoming disruptive to traditional

10 accommodations (e.g., hotels) (Chang \& Sokol, 2020; Craig \& Karabas, 2021) due in part to its

11 naturally socially distant, lower risk setting (Ma et al., 2021a; CCG, 2019, 2020a, b; Gossling et

12 al., 2020; Yu et al., 2021). COVID-19 risks (actual and perceived) are lower for camping than

13 other accommodations because it is well ventilated, shared indoor spaces are not as prevalent

14 (e.g., lobbies, bathrooms), and there is minimal close contact with other individuals (CCG,

15 2020a; WHO, 2021a).

16 In addition to weather, traveler characteristics also influence camping trip plans. Studies

17 in North America demonstrate that weather, changing climatic conditions, and socio-

18 demographic factors are related to camping and other recreation decisions (CCG, 2019; Craig \&

19 Feng, 2018; Craig, 2019; Ma et al., 2021a,b; Hewer et al., 2017). For instance, Hewer et al.

20 (2017) show: (1) there are differences in camping type (i.e., tent or other) and recreational

21 activity (i.e., swimming/wading or other) based on age, and (2) there is variance in acceptable

22 weather for camping based on gender and age. Craig and Karabas (2021) note that age, income,

23 and employment are related to glamping, a form of camping with luxurious amenities. 
1 Considering past significance of intrinsic factors on camping decisions, this study captures and

2 controls for traveler characteristics including age, income, employment, gender, and ethnicity.

3 Like other sub-sectors of nature-based tourism (e.g., alpine skiing), weather is often the

4 strongest predictor of camping (Ma et al., 2021a,b; Hewer et al., 2017; Tashman \& Rivera, 2016;

5 Wilkins et al., 2018). There are multiple factors that influence favorable conditions for camping,

6 so we operationalize weather and climate using the composite Camping Climate Index (CCI; Ma

7 et al., 2020). Weather occurs from minutes to weeks and climate from months (i.e., climatic

8 variability) to decades (i.e., climate change). The CCI is calculated using seven weather variables

9 (see Table I) and has been validated demonstrating better model fit compared to other tourism

10 indices (e.g., Matthews et al., 2019; Mieczkowski, 1985; Rutty \& Scott 2010) at for-profit (Ma et

11 al., 2020) and non-profit (Ma et al., 2021b) campsites in the United States. The CCI is

12 formulated to best describe camping weather and climate favorability because it empirically

13 captures extreme, overriding temperature, precipitation, and wind events. Additional details

14 about the CCI are provided in the methods section.

$15 \quad 1.2$ Disasters

16 COVID-19 is an external biological disaster and a man-made crisis (Aliperti et al., 2019;

17 Rosollo et al., 2020; Sharuf et al., 2003). Disasters and crises are similar but distinct with no

18 agreed upon definitions (Faulkner, 2001; Ritchie, 2004; Ritchie \& Jiang, 2019; Shaluf et al.,

19 2003). However, prior studies have analyzed the literature to establish features and

20 characteristics for the two concepts (e.g., Al-Dahash et al., 2016; Aliperti et al., 2019; Ritchie \&

21 Jiang, 2019; Shaluf et al., 2003).

22 A comprehensive literature synthesis "reveals that the key features of any disaster are its

23 sudden nature, being unforeseen, causing loss and damage, coping capacity, system recovery, 
1 external assistance and involvement of multi stakeholders" (Al-Dahash et al., 2016, p. 1194).

2 Common characteristics of disasters include they (1) only have negative effects, (2) are caused

3 by the accumulation of previously overlooked circumstances or events, and (3) cause widespread

4 harm (Sharuf et al., 2003). Criteria for disasters quantifies harm from events, with examples

5 including substantial (1) loss of life (i.e., 25 or more), (2) injuries (i.e., 125 or more), (3)

6 evacuations (i.e., 10,000 or more), and (4) economic impact (i.e., US\$1 million or more) (Sharuf

7 et al., 2003).

8 Crises are closely related to disasters, especially when they result from a disaster.

9 According to Al-Dahash et al. (2016), "the key features of a crisis are uniqueness, danger,

10 troublesome or causing damage, being unexpected, and usually emotional” (p. 1195).

11 Characteristics of crises include they (1) are man-made, (2) can be positive or negative, and (3)

12 can stem from economic issues, political issues, or disasters (Sharuf et al., 2003). Criteria for

13 crises are both qualitative and quantitative, with thresholds for harm typically lower than those

14 for disasters (Sharuf et al., 2003). As a crisis, COVID-19 represents community and corporate

15 crises (Sharuf et al., 2003) that uniquely impacts stakeholder groups (e.g., individuals,

16 communities, governmental agencies, businesses).

A key distinction of a disaster that COVID-19 meets is that it "can be described as

18 occurring outside the organization" (Ritchie, 2004, p. 670), where organization encompasses the

19 stakeholder groups described above. As a disaster, COVID-19 has both natural and man-made

20 traits, thus represents a hybrid biological disaster (Sharuf et al., 2003). Tourism researchers have

21 previously explored a variety of disaster types — natural, man-made, and hybrid —including

22 biological (e.g., epidemic), climatological (e.g., drought or wildfire), geophysical (e.g.,

23 earthquake or volcano), hydrological (e.g., flood), industrial (e.g., accident), meteorological (e.g., 
1 storm or heatwave), and terroristic (e.g., 9/11 terrorist attacks) (e.g., Floyd et al., 2008; Ritchie \&

2 Jiang, 2019; Rosollo et al., 2020; Sharuf et al., 2003; van Lent, 2017). The tourism industry is

3 susceptible to each disaster type (Yeh, 2020), though biological disasters are unique because they

4 do not typically cause physical harm to infrastructure (e.g., buildings, forests), and the effects

5 may not be as easily or immediately observable.

6 The proliferation of COVID-19 has led health researchers to consider the multiplicative

7 effects of disasters (Sohrabizadeh et al., 2021). Few tourism researchers, however, have studied

8 the coincident of events (Ritchie \& Jiang, 2019). One exception is Cohen and Neal (2010),

9 whose observational research found that concurrent economic and political crises magnified the

10 adverse effects on the tourism and hospitality industries in Thailand. Bansal (2020) called on

11 management researchers to explore the coincident of COVID-19 and climate change, though to-

12 date, our study is the first known to provide an empirical framework to study the dual effects on

13 a tourism outcome (i.e., travel plans). Climate change — and the effects of climate change-will

14 continue to variably exacerbate the economic and human risks of each disaster type (Bansal et

15 al., 2020; Becken et al., 2014; Reidmiller et al., 2018), justifying the theory development and the

16 empirical investigation of COVID-19 inclusive weather and climate.

\section{$17 \quad \mathbf{1 . 3}$ Theory Development}

18 The Camping-Weather-Disaster (CWD) framework extends the Construal Level Theory

19 (CLT; Trope \& Liberman, 2010) by exploring the effects of two stimuli on post-disaster travel

20 plans. The original CLT considers only one stimulus. The CWD is applicable to longitudinal

21 studies because it captures changes to stimuli as they elapse (see Figure 1). The framework

22 includes the two primary CLT components: construal of and psychological distance from a

23 disaster. Construal is an individual's level of understanding, where stimuli response is either 
1 outside (abstract) or within (concrete) their mental horizon (Trope \& Liberman, 2010). Abstract

2 construal is closely associated with uncertainty, the concept we use in this study to assess

3 construal. For example, Glaser et al. (2015) established a relationship between uncertainty and

4 greater perceived spatial distance (i.e., an abstract construal about distance). Comparably,

5 Liberman and Trope (1998) found that attainable future temporal end-states are more concretely

6 construed. An example of concrete construal is knowing the exact dates, duration, and distance

7 of travel. Concrete construal is more closely related to a specific action than abstract construal

8 (Craig et al., 2019; Chang et al., 2015; Kim et al., 2016; Mildenberger et al., 2019).

[Insert Figure 1 about here]

10 The second component of the CLT is psychological distance, or "the subjective distance

11 stimuli maintain from a person’s direct experience" (van Lent et al., 2017). Psychological

12 distance's "reference point is the self, here and now, and the different ways in which" a stimulus

13 may be removed from that point (Trope \& Liberman 2010, p. 440). The original CLT conception

14 of psychological distance includes temporal (when), spatial (where), social (to whom), and

15 hypothetical (whether) proximity ranging from proximate to distant (Liberman \& Trope, 2008;

16 Trope \& Liberman, 2010). Psychological distance is specific to a stimulus, or in our case,

17 multiple stimuli. Tourism research using the CLT has operationalized psychological distance as

18 nearby in time, physical distance, and within one's social group (Dogan \& Erdogan, 2020; Kim

19 et al., 2016). The subjective nature of psychological distance does not inherently prevent an

20 individual's experience and/or perceptions to differ from these operationalizations (Trope \&

21 Liberman, 2010). Construal and psychological distance are related but not synonymous.

22 Typically, psychological distance is more closely related to high-level, abstract construal and 
1 decreased distance is related to low-level, concrete construal (Liberman \& Trope, 2008; Trope \&

2 Liberman, 2010).

3 The CWD adapts time, space, and social inclusion from the CLT but not hypotheticality.

4 Hypotheticality is omitted because stimuli (i.e., weather and COVID-19 cases) are not

5 hypothetical events that may or may not happen in the future. Stimuli range from small (e.g.,

6 daily average temperature, minimal COVID-19 cases) to large (e.g., global increase of long-term

7 daily average temperature, COVID-19 hotspots). Including scale helps overcome a criticism of

8 the CLT pertaining to individual construal and agency to act towards large-scale stimuli such as

9 climate change. For instance, Brugger (2020, p. 3) refutes "the argument that climate change is

10 too distant or abstract to be personally relevant, and that reducing this distance could increase

11 personal relevance and action.” In support of Brugger (2020), other researchers have

12 demonstrated that even when individuals understand stimuli (e.g., climate change) as concrete

13 and proximate, stimulus scale can prohibit action (Bansal et al., 2018; Bowen et al., 2018). By

14 integrating actual stimuli, psychological distance can be assessed while controlling for scale of

15 the stimuli across both time and space.

16 The CWD includes two observable stimuli, individual construal, and individual

17 psychological distance (time, space, social inclusion), extending the CLT by offering a clear

18 mechanism for the dynamic exploration of multiple stimuli (e.g., weather and COVID-19) that is

19 indicative stimuli scale. We assert that analyzing the variable impacts of weather, extremes, and

20 disasters longitudinally, spatially, and concurrently alongside societal factors (i.e., construal and

21 psychological distance), destination managers and authorities can increase their levels of

22 understanding about their own complex socioecological systems (Craig, 2019). Positive

23 consequences to understanding include organizational learning and increased business agency to 
1 take adaptive and/or mitigative actions towards future natural conditions or disasters (Berger et

2 al., 2016; Bhaskara \& Filimonau, 2021; Craig, 2019). Applying the CWD, the study also makes

3 a significant methodological contribution as the first known to integrate social, climate, and

4 epidemiological data to assess a post-COVID-19 outcome.

\section{$5 \quad 1.4$ Hypotheses}

The two social factors included in the CWD are individual construal and psychological

7 distance. Using a survey instrument deployed between April $27^{\text {th }}$ and April $30^{\text {th }}, 2020$, the CWD

8 operationalizes construal and psychological distance in terms of time, space, and social inclusion

9 relative to COVID-19. The timing of data collection marks the height of travel restrictions in the

1048 contiguous United States. Specifically, (1) 37 states had stay-at-home orders, (2) four states

11 had stay-at-home recommendations, and (3) seven states had some level of restrictions and

12 closures though no stay-at-home orders (Miller, 2020).

13 On the survey, respondents were able to respond "uncertain" when asked about timing of

14 travel (time) and distance of travel (space) after travel restrictions are lifted. Respondents were

15 also asked about travel restrictions to establish if they were in a social in- or out-group (i.e.,

16 social inclusion) relative to the disaster. Consistent with the CLT, respondents who reported

17 higher levels of travel restrictions are considered the social in-group and those who reported

18 fewer or no restrictions are considered the social out-group. Prior disaster studies have also

19 operationalized social inclusion based on disaster experience (e.g., resident of a county that

20 experienced a large wildfire or not; Spialek et al., 2021). Providing a definition for time, space,

21 and social inclusion indicates that each of the constructs has contracted to fit within one's mental

22 horizon, thus representing concrete understanding (Trope \& Liberman, 2010). The uncertain

23 response category allows us to operationalize construal into two groups: those who have a 
1 concrete understanding of when, where, and if they can travel and those who do not (i.e.,

2 uncertain) (e.g., Glaser et al., 2015; Liberman \& Trope, 1998).

Hypothesis 1a: Lower levels of construal for time will be positively related to post-

$4 \quad$ disaster camping trip plans.

Hypothesis $1 b$ : Lower levels of construal for space will be positively related to postdisaster camping trip plans.

Hypothesis 1c: Lower levels of construal for social inclusion will be positively related to post-disaster camping trip plans.

Based on the literature reviewed, we hypothesize that socio-demographic factors,

weather, the COVID-19 disaster, and psychological distance (temporal, spatial, and social) will

11 be significantly related to post-disaster camping trip plans. plans.

Hypothesis 2b: Weather will be related to post-disaster camping trip plans.

\section{2. Methods} plans.

\subsection{Survey Procedure}

A market research firm developed and administered an online survey between April 27

22 and April 30, 2020. A private tourism business that operates campsites funded the survey to

23 capture traveler responses to COVID-19 at the height of travel restrictions in the United States. 
1 Questions for the survey were crafted by the marketing research firm based on the tourism

2 business' information needs, and included single-item questions rather than previously validated

3 scales. The use of single-item questions is a commonly used procedure for opinion polls

4 conducted by consultants for commercial or political purposes. With the written permission from

5 the tourism business, the market research firm provided de-identified data for the purpose of

6 non-commercial scholarly inquiry. No additional information is provided to ensure

7 confidentiality is protected.

8 The research firm solicited participation via email from their proprietary database of

9 known leisure travelers age 18 or older with a total of 7,659 participants initially responding. All

10 surveys were completed online. The number of outbound email solicitations sent to achieve the

11 initial 7,659 responses is unknown, so it is not possible to calculate a true response rate. The final

12 sample $(\mathrm{n}=2,442$ out of 7,659$)$, however, represents a completion rate $31.9 \%$ with a margin of

13 error of $3 \%$ at the $99 \%$ confidence level. Our relatively low margin of error and $99 \%$ confidence

14 level are measures of acceptable survey reliability.

$15 \quad 2.2$ Measures and Sample

16 In addition to socio-demographic questions (see Table II), there are independent variables

17 for time of travel (time), distance of travel (space), and travel restrictions (social in- and out-

18 groups). Time was operationalized with the question root "How long will it take for you to go

19 camping once the restrictions in your area are lifted?" with eight response categories I feel that it

20 is safe to go camping (1) now, (2) within the next 1 or 2 weeks, (3) within the next month, (4) in

21 the next 1-2 months, (5) in the next 3-4 months, (6) in the next 5-6 months, (7) more than 6

22 months, and (8) uncertain. Space was operationalized with the question root "What is the

23 maximum distance you are willing to travel for a camping trip once the restrictions are lifted?" 
1 with nine response categories: (1) within 25 miles, (2) 26-50 miles, (3) 51-100 miles, (4) 101-

2150 miles, (5) 151-200 miles, (6) 201-300 miles, (7) more than 300 miles, (8) none, I do not feel

3 that there is a maximum distance, and (9) uncertain. Social inclusion was operationalized with

4 the question root "How do you view the current level of restrictions regarding what you can and

5 cannot do during the COVID-19 pandemic where you reside?" with response categories from (1)

6 severe to (5) no restrictions, and (6) uncertain.

[Insert Table II about here]

8 The dependent variable of interest is post-disaster camping trip plans (i.e., future

9 camping trips planned where COVID-19 conditions permit). An explanation of what constitutes

10 a camping trip was first provided: "Camping trips are when you spend at least one night outside

11 of your primary residence and stayed in accommodations such as a tent, trailer, RV, vehicle, or

12 cabin/cottage (or other unique accommodation) at a campground." Respondents were then asked

13 to indicate the number of post-COVID-19 camping trips planned with the question root:

14 “Planned trips after COVID-19?” with an [Enter] option.

\section{$15 \quad 2.3$ Camping Climate Index (CCI)}

16 The CCI is an outdoor tourism climate index that quantifies the desirability of weather

17 and climatic conditions for camping (Ma et al., 2020). The CCI: (1) equally weights thermal

18 comfort and sunshine hours and (2) incorporates overriding factors for minimum temperature,

19 maximum temperature, precipitation, and windspeed (see Table I for CCI measures). CCI values

20 range from 7-10 (ideal), 5-7 (good), 3-5 (acceptable), and 0-3 (poor). The climate variables in the

21 CCI (e.g., thermal comfort and sunshine hours) are comparably rated from 0 to 10 indicating the

22 relationship that each variable shares with travel behavior despite unit (e.g., degrees and hours).

23 As shown in the equation, the CCI takes the average of thermal comfort and sunshine hours, and 
1 when extreme overriding factors are observed, the CCI is forced to a maximum of 3 (i.e., poor).

2 For a full explanation of the CCI, see Ma et al. (2020). 22 (Oster et al., 2020).

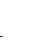

\subsection{COVID-19 Cases}

$$
\begin{aligned}
& C C I=T C^{*} .5+S^{*} .5 \text { (minimum }[C C I, 3] \text { if } T M I N<8^{\circ} C \text { or } T M A X>34^{\circ} C \text { or } P>10 \mathrm{~mm} \\
& \text { or } W>23 \mathrm{~km} / \mathrm{h}
\end{aligned}
$$

Daily weather data were obtained from January 1, 1984 to December 31, 2019 in a 0.5*0.5 gridded format through the Power Data Access Viewer (NASA, 2020). The data cover the 48 contiguous United States (3,264 grid points in total). The state-level CCI was calculated from the grid point coordinates by using the "maps" and "sp" packages in R. Then, we aggregated the daily CCI for each state to obtain spring monthly means for (1) March, April, and May in 2020 (see Figure 2).

\section{[Insert Table II and Figure 2 about here]}

We obtained COVID-19 cases through the Coronavirus Resource Center (Johns Hopkins, 2020). We recorded confirmed cases for each of the 48 contiguous states one month apart on April 1 and April 30, 2020. This is the same method used in climate studies - and applied to March CCI in this study — to retrospectively analyze the lagged effect of past conditions. The lagging technique introduces an additional longitudinal element to the analysis to capture past and present scale of COVID-19 cases. April $1^{\text {st }}$ and $30^{\text {th }}$ represent days when (1) every state in the United States had reported COVID-19 cases and trajectory and transmission was beginning to display exponential growth (Center for Disease Control [CDC], 2020; Johns Hopkins, 2020) and (2) survey data collection halted and the peak of daily cases had passed in the Northeast

Over half (i.e., 574 thousand) of the documented cases were from 11 states in the Northeast climate region: Connecticut, Delaware, Maine, Maryland, Massachusetts, New 
1 Hampshire, New Jersey, New York, Pennsylvania, Rhode Island, and Vermont. On April $1^{\text {st }}$,

22020 and April $30^{\text {th }}, 2020$ there were 125.5 and 574 thousand confirmed COVID-19 cases in the

3 Northeast United States and 96.8 and 544.3 thousand elsewhere, respectively (John Hopkins,

4 2020). We consider the reported cases in the Northeast large scale as compared to small scale for

5 all other COVID-19 case observations. Monthly CCI data and COVID-19 cases were integrated

6 into the social science dataset. The sorting procedure represents a natural research design, where

7 we were able to investigate differences among leisure travelers based on regional scale of

8 COVID-19. Natural research designs are common in disaster studies allowing researchers to

9 compare regions disproportionately impacted by natural disasters or climate change (Hein et al., 10 2019).

\section{$11 \quad 2.5$ Statistical Analysis}

12 The two statistical methods used to test hypotheses are independent sample t-tests and

13 binary linear regression. Independent sample t-test determine if there is a significant difference in

14 a dependent variable for two groups (i.e., high and low construal). Binary logistic regression

15 determines model fit (Nagelkerke $\mathrm{R}^{2}$ ) compared to a null model (i.e., model without independent

16 variables) and the likelihood $(\operatorname{Exp}(B))$, or odds, of dependent variable occurrence (i.e., post-

17 COVID-19 camping trip plans). Binary logistic regression is commonly used in social and health

18 sciences, making it an appropriate method for our interdisciplinary dataset (King, 2008). The

19 software suite used to conduct the analysis was IBM SPSS version 25.

20 To test Hypothesis 1, we ran independent samples t-tests to determine if there were

21 differences for the number of camping trips planned post-COVID-19 between those who

22 answered "uncertain" for the time $(1 a)$, space $(1 b)$, and social inclusion $(1 c)$ (i.e., high level

23 construal) and those who specifically responded (i.e., low level construal). We considered 
1 responses to be low construal if a specific time, distance, or level of travel restrictions was

2 defined. For example: responses from (1) travel within 1 to 2 weeks of restrictions being lifted to

3 (7) travel more than six months after travel restrictions are lifted for time were considered low

4 construal; responses from (1) travel within 25 miles when travel restrictions are lifted to (8) no

5 maximum travel distance once travel restrictions are lifted were considered low construal, and;

6 responses from (1) severe travel restrictions to (5) no travel restrictions were considered low

7 construal.

8 A natural research design was used to address Hypotheses $2 a-d$ because there were

9 disparate COVID-19 case distributions in the United States at the time of the survey. A central

10 feature of natural research designs is they assess the variable effects of individual experiences to

11 stimuli such as weather, disasters, or policy (Messer, 2008). As described above, we conducted

12 analysis for the (1) Northeast climate region and (2) the remaining 37 states not in the Northeast

13 climate region. Climate regions were used because regional sections (1) are spatially proximate

14 and share comparable natural environment conditions (Karl and Koss, 1984) and (2) provide a

15 large enough sub-sample to maintain an acceptable margin of error when analyzed separately.

16 To test Hypotheses $2 a-d$, we used binary logistic regression to explore camping plan

17 differences in (1) travelers who indicated they had one or more camping trips planned post-

18 disaster, and (0) travelers who did not. We also recoded ethnicity and employment due to

19 underrepresented response categories: (1) Caucasian/White and (0) other ethnic background, and

20 (1) male and (0) female or other. Due to underrepresented response categories, and the influence

21 of COVID-19 employment changes, employment was recoded (1) unemployed or furloughed

22 because of COVID-19 and (0) not unemployed or furloughed because of COVID-19. Age and

23 income were not recoded. 
To prepare for analysis Hypotheses $2 a-d$, we first removed respondents with "uncertain" responses $(n=628)$. Then, we sorted respondents $(n=1,814)$ into the Northeast climate region

$3(n=442$, margin of error $=5 \%$, confidence level $=95 \%)$ and the rest of the climate regions $(n=$

41,372 , margin of error $=3 \%$, confidence level $=99 \%$ ). Next, we used the enter method of binary

5 logistic regression for the Northeast climate region and the rest of the United States. The enter

6 method includes four blocks: (1) socio-demographic factors, (2) state-level CCI for March,

7 April, and May, (3) state-level COVID-19 cases for April 1 and April 30, 2020, and (4)

8 psychological distance in terms of time, space, and social inclusion. Skewness and kurtosis for

9 the three scale items were acceptable (see Table III). The block method allows for the

10 incremental assessment of model significance and fit.

[Insert Tables III and IV about here]

\section{3. Results and Analyses}

\section{$13 \quad 3.1$ Hypothesis 1}

Hypothesis 1 proposes lower-level, concrete construal will be positively and significantly

15 related to post-disaster (i.e., post-COVID-19) camping trip plans for time ( $1 a)$, space ( $1 b)$, and

16 social inclusion ( $1 c$ ). Hypothesis $1 a$ and $1 b$ are supported (i.e., time and space), but Hypothesis

17 Ic (i.e., social inclusion) is not. Using independent samples t-tests, we found that: travelers who

18 defined a time for travel were significantly more likely to have post-disaster camping trip plans

$19(\mathrm{n}=1953$, mean $=2.10$ planned trips $)$ than those who responded uncertain $(n=489$, mean $=.98$

20 planned trips; $t=1.739, d f=574.986, p=.083$ ); travelers who defined a distance for travel were

21 significantly more likely to have post-disaster camping trip plans $(n=2117$, mean $=2.09$

22 planned trips $)$ than those who responded uncertain $(\mathrm{n}=325$, mean $=.46$ planned trips; $t=7.010$,

$23 d f=2428.55, p=.001)$, and; there was no difference between travelers that rated travel 
1 restrictions $(\mathrm{n}=2400$, mean $=1.87)$ and those who responded uncertain $(\mathrm{n}=42$, mean $=2.17 ; t$

$2=-.466, d f=49.697, p=.643)$.

3 Though not causal, results from Hypothesis $1 a$ and $1 b$ suggest psychological distance

4 based on time and space is positively associated with the number of camping trips planned post-

5 disaster. In terms of time, travelers are likely to think more concretely about events that are more

6 temporally proximate. Concrete construal in turn is associated with more immediate action such

7 as planning a camping trip (Craig, 2019; Kim et al., 2016; Trope \& Liberman, 2010). In terms of

8 space, people tend to focus on abstract features of physically distant stimuli and locations (Kim

9 et al., 2016; Trope \& Liberman, 2010).

10 We refrain from drawing conclusions for Hypothesis 1c (i.e., social inclusion) given the

11 uneven cells between those who rated the level of restrictions in their area and others who were

12 uncertain. However, among our sample the finding that only 42 out of 2,442 travelers were

13 uncertain about travel restrictions demonstrates widespread lower-level, concrete construal.

\section{$14 \quad 3.2$ Hypothesis 2}

\section{$15 \quad$ 3.2.1 Northeast Climate Region}

16 Hypothesis 2 posits that socio-demographic factors $(2 a)$, weather $(2 b)$, disasters $(2 c)$, and

17 psychological distance $(2 d)$ will be related to post-disaster camping trips. These hypotheses are

18 supported, but inclusion of weather and disaster variables in models is also related to disaster

19 scale. For the Northeast climate region, a significant final model emerged with good fit $\left(R^{2}\right.$

$20=.316, p=.000, n=442$ ) where there are significant factors from three of the four blocks:

21 significant socio-demographic factors include age $(\operatorname{Exp}(B)=-.982, p=.016)$, income $(\operatorname{Exp}(B)=$

$221.474, p=.024)$, and ethnicity $(\operatorname{Exp}(B)=-.325, p=.000)$; there are no significant weather

23 factors; significant COVID factors include April 1 cases $(\operatorname{Exp}(B)=1.106, p=.005)$ and April 30 
1 cases $(\operatorname{Exp}(B)=-.975, p=.021)$, and; psychological distance factors include time $(\operatorname{Exp}(B)=-$

$2.824, p=.001)$, space $(\operatorname{Exp}(B)=1.211, p=.083)$, and social inclusion $(\operatorname{Exp}(B)=-.905, p=.04)$.

3 As shown in Table IV, each successive block significantly explains additional model variability.

4 In Block 2 April CCI $(\operatorname{Exp}(B)=1.568, p=.041)$ is positively related to post-disaster

5 camping trips but May CCI $(\operatorname{Exp}(B)=-.406, p=.000)$ is negatively related. The odds-ratios, or

6 likelihood of camping trips, mean that travelers that experienced better CCI in April are 1.568

7 times more likely to have post-disaster camping trip plans whereas future CCI in May are 2.63

8 times less likely to have post-disaster camping trip plans. This directionality is shared for April 1

9 and April 30 COVID-19 cases in Block 3 where the former $(\operatorname{Exp}(B)=1.107, p=.003)$ is

10 positively related to post-disaster camping trip plans and the latter is negatively related $(\operatorname{Exp}(B)$

$11=-.975, p=.016)$. The significant relationships that April 1 and April 30 COVID-19 cases share

12 with camping trip plans in Block 3 - combined with CCI becoming insignificant - are an

13 indication that scale of COVID-19 has an overriding impact on traveler plans despite favorable

14 current (April CCI) and/or improving weather (May CCI). This overriding effect is why May

15 CCI was inadvertently negatively related to post-disaster camping trip plans in Block 2 but then

16 became insignificant in Block 3 with the addition of April $1^{\text {st }}$ COVID-19 cases (i.e., smaller

17 scale) and April 30 ${ }^{\text {th }}$ COVID-19 cases (i.e., larger scale).

18 There are two key take-aways from the findings from the Northeast climate region. First,

19 after controlling for socio-demographic factors, the most salient predictor of post-disaster

20 camping trip plans are April $1^{\text {st }}$ and April $30^{\text {th }}$ state-level COVID-19 cases. COVID-19 scale-

21 both small and large - superseded all CCI variables in the final model. The natural research

22 design allows us to capture scale at two points in time showing post-disaster camping trips are 
1 positively related to the relatively smaller scale of COVID-19 cases on April $1^{\text {st }}$ and negatively

2 related to the larger scale of COVID-19 cases on April $30^{\text {th }}$.

3 Second, each of the three psychological distance variables are significant thus supporting

4 the empirical inclusion in the CWD framework. Post-disaster camping trips decrease with

5 expected time of travel (time), increase with distance willing to travel (space), and decrease with

6 severity of travel restrictions (social inclusion). As the CLT predicts (Trope \& Liberman, 2010),

7 travelers who concretely report closer temporal proximity of travel (e.g., within 1 or 2 weeks) are

8 significantly more likely to have post-disaster camping trips already planned. Also, travelers in

9 close social proximity (i.e., the social in-group with more severe levels of travel restrictions) are

101.10 less likely to have travel plans compared to the more socially distant (i.e., the social out-

11 group with lower levels of travel restrictions) travelers. Interestingly, more distant geographic

12 proximity of travel is positively related to post-disaster camping trip plans. In response to

13 COVID-19, travelers have expressed a desire for non-communal spaces and less crowded

14 locations (CCG, 2020b; Craig, 2021), characteristics that may be even more important than the

15 distance to a campground. Considering the scale of COVID-19 in the Northeast climate region

16 on April $30^{\text {th }}$, it may also be that travelers wanted to put more physical distance between

17 themselves and the region most impacted by COVID-19 when camping.

\section{$18 \quad 3.2 .2$ All Other Climate Regions}

For the remainder of the climate regions in the United States, a significant final model

20 emerged with acceptable fit $\left(R^{2}=.209, p=.001\right)$ where there are significant factors from three of

21 the four blocks: significant socio-demographic factors include age $(\operatorname{Exp}(B)=-.990, p=.009)$,

22 income $(\operatorname{Exp}(B)=1.19, p=.000)$, gender $(\operatorname{Exp}(B)=2.193, p=.000)$, and ethnicity $(\operatorname{Exp}(B)=-$

$23.514, p=.000)$; the lone significant weather factor includes March CCI $(\operatorname{Exp}(B)=1.171, p=$ 
1 .089); there are no significant COVID-19 factors, and; psychological distance factors including

2 time $(\operatorname{Exp}(B)=-.815, p=.000)$ and social inclusion $(\operatorname{Exp}(B)=-.934, p=.008)$ are also

3 significant. As shown in Table IV, only the block with COVID-19 cases did not significantly

4 improve model fit.

$5 \quad$ For the all other climate regions' regression model, after controlling for socio-

6 demographic factors $\left(R^{2}=.142, p=.000\right)$, psychological distance is the strongest determinant of

7 post-disaster travel $\left(R^{2} \Delta=.045, p=.000\right)$ followed by CCI in March $\left(R^{2} \Delta=.020, p=.000\right)$.

8 Those with plans to travel in the more proximate future are 1.227 times more likely to have post-

9 disaster camping trip plans; travelers with more severe travel restrictions are 1.07 times less

10 likely to have post-disaster camping trip plans; and travelers that experienced better CCI in

11 March are 1.171 times more likely to have post-disaster camping trip plans.

12 Compared to the Northeast climate region model, COVID-19 is not a significant

13 predictor in the all other climate region model. However, state-level CCI for March 2020 is a

14 significant predictor of post-disaster camping trip plans in the final all other regions model while

15 there are no significant weather variables in the final Northeast model. Close temporal proximity

16 and proximate social inclusion (i.e., the in-group with more severe travel restrictions) are also

17 significant predictors though space (i.e., miles willing to travel after travel restrictions are lifted)

18 is not in the all other climate region model. Combined, the findings suggest that travelers outside

19 the Northeast climate region with post-disaster camping trip plans are influenced by favorable

20 camping weather resources (i.e., CCI), are planning to camp within shorter amounts of time, and

21 come from areas with fewer travel restrictions. 


\section{4. Theory Advancement}

Introducing the CWD, we provide a framework that can help build organizational

3 understanding of complex socioecological challenges, addressing calls to concurrently consider

4 the interconnectedness of salient natural and societal factors (Bansal et al., 2020). The tourism

5 industry is one of the most susceptible to weather, climate change, and non-

6 meteorological/climatological disasters like COVID-19 (Reidmiller et al., 2018; UNWTO,

7 2020), providing useful perspectives compared to other industries. While the results and

8 implications are within the context of camping, the theoretical advancements - and the

9 applicability of the CWD - extend to other subsectors of tourism and also other industries,

10 especially those reliant on the natural environment.

11 Developing and operationalizing the CWD, there are two theoretical advancements to the

12 CLT (Trope \& Liberman, 2010). First, the CWD framework accounts for multiple empirically

13 observable stimuli. In this study, stimuli include weather desirability (i.e., CCI) and a biological

14 disaster (i.e., COVID-19). The framework is operationalized with two quadrants and stimuli, but

15 more stimuli could be included (see Figure 1). For instance, a salient climate change-induced and

16 weather-related natural disaster overlapping the COVID-19 pandemic in California, United

17 States is wildfire. Freedman (2020) notes that "California just witnessed one of its hottest

18 weekends in memory, which intensified destructive wildfires that occurred" (par. I) necessitating

19 the rescue of over 200 trapped campers on September 6, 2020. The extreme temperatures-as

20 high as $49^{\circ} \mathrm{C}$ or $15^{\circ} \mathrm{C}$ above the extreme temperature threshold for the CCI (Ma et al., 2020)-

21 prompted a National Weather Service alert for the entirety of the state of California (Freedman,

22 2020). Despite the dangerous wildfire conditions, many campers, destination managers, and

23 authorities did not heed warnings. The lack of reaction highlights the need for more concrete 
1 understanding of temporally and spatially proximate climate and weather-related risks among

2 individuals to inform mitigative and/or adaptive actions (e.g., campsite closures).

3 The second advancement is the inclusion, operationalization, and observation of disaster

4 scale alongside individual psychological distance, a socioecological approach that includes the

5 natural environment. Where COVID-19 scale was the largest (i.e., the Northeast climate region),

6 COVID-19 cases are the most predictive factor of post-disaster camping trip plans when

7 controlling for socio-demographics. Where scale was smaller (i.e., the rest of the contiguous

8 United States), COVID-19 is not a significant factor. Findings about scale are consistent with

9 consumer responses for other forms of hospitality. For instance, Kim and Lee (2020) found that

10 greater COVID-19 scale is related to avoiding public dining and vice versa. In general, the

11 results build on previous tourism disaster studies (e.g., Craig, 2021; Craig \& Karabas, 2021;

12 Craig et al., 2021; Floyd et al., 2008; Granvorka \& Strobl, 2013; van Lent et al., 2017)

13 demonstrating differences in future traveler decisions based on the scale of disaster despite type

14 (e.g., extreme weather, pandemic, terrorism). The results are also consistent with two recent

15 wildfire studies that found resident proximity to wildfire (i.e., those located in the same country

16 as a large, documented wildfire or not) is related to concrete actions including (1) support for

17 enhanced public/private collaboration to manage wildfires and (2) disaster communication

18 before, during, and after a wildfire (Craig et al., 2020; Spialek et al., 2021).

Guided by previous tourism research about accommodations (Dogan \& Erdogan, 2020;

20 Kim et al., 2016), we operationalized temporal and spatial psychological distance as duration

21 until travel and distance to destination. Comparable to other disaster stimuli that have influenced

22 travel decisions - the 9/11 terrorist attacks in the United States in 2001 (Floyd et al., 2008) and

23 the 2014 Ebola epidemic (van Lent et al., 2017)—we report significant relationships between 
1 camping travel decisions, time, and distance. As expected, in the Northeast where COVID-19

2 scale is greater, travelers willing to camp soon are significantly more likely to have post-disaster

3 camping trip plans. Contrary to findings about hotel accommodations (Dogan \& Erdogan, 2020;

4 Kim et al., 2016), however, spatial psychological distance of travel is positively related to post-

5 disaster camping decisions. Post-hoc analysis of a CDC report about COVID-19 hotspots in the

6 United States (Oster et al., 2020) offers some additional insights about the Northeast. When the

7 survey was conducted, not only were there over double the number of cases in the Northeast

8 region (Johns Hopkins, 2020), but $84 \%$ of the population lived in a county designated as a

9 "hotspot" (Oster et al., 2020). It is conceivable that the widespread spatial distribution of

10 COVID-19 hotspots throughout the region is why campers are willing to travel greater physical

11 distances (Craig et al., 2021).

\section{$12 \quad 4.1$ Camping Implications}

13 The results from Hypotheses la-c suggest that destination managers and authorities

14 wanting to develop strategies targeting post-disaster campers should (1) identify travelers with a

15 clear timeframe and distance for travel and (2) communicate specific, concrete messages to these

16 travelers. At the time the survey was conducted, travelers uncertain about time and distance were

17 less likely to have camping trip plans highlighting the potential to communicate specific,

18 concrete messages to promote temporal and spatial certainty about camping. Regardless temporal

19 or spatial construal, messages should highlight advantageous camping resources such as

20 favorable weather (i.e., CCI) and for biological disasters like COVID-19, the ability to practice

21 social distancing. For man-made disasters (e.g., industrial explosions, terroristic attacks), the

22 natural and rural setting of camping is also an advantageous travel resource.

23 When considering the entirety of the contiguous United States, there are three consistent

24 findings of interest: (1) travelers who are willing to camp in the near future are more likely to 
1 have post-disaster camping trip plans, (2) travelers living in areas with fewer travel restrictions

2 are more likely to have post-disaster camping trip plans, and (3) distance traveled may not be as

3 big of a hindrance as previously thought within the context of camping during a biological

4 disaster (i.e., COVID-19). Camping is unique (e.g., nature-based, socially distant, accessible by

5 personnel vehicle) compared to other forms of accommodations and recreation (CCG, 2019,

6 2020a,b; Craig, 2021; Gossling et al., 2020). These characteristics offer a plausible explanation

7 for why future traveler camping decisions are not constrained by physical distance like previous

8 disasters (e.g., 9/11, Ebola) for other accommodation types (Dogan \& Erdogan, 2020; Floyd et

9 al., 2008; Kim et al., 2016; van Lent et al., 2017).

$10 \quad$ 4.2 Limitations and Future Research

11 This study is not without limitation. Primarily, the study is exploratory where cross-

12 sectional social science data was collected to address managerial needs of a private tourism

13 business. The tourism business quickly reacted to COVID-19 by collecting survey data at the

14 height of travel restrictions to inform their future strategic response. The managerial needs and

15 operationalization of these needs by the marketing firm (i.e., crafting the survey questions)

16 resulted in data being collected at one point in time, the use of single-item questions, and a

17 response option for the space construal independent variable without a clearly defined mileage

18 distance for travel after restrictions are lifted (i.e., (8) none, I do not feel that there is a maximum

19 distance). Also, the context of the dependent variable, "Planned trips after COVID-19," prompts

20 travelers to indicate trips planned after COVID-19. Though, it is not possible to infer whether

21 travelers attributed "after COVID-19" trips to those planned before the onset of COVID-19 but

22 occurred after where permissible. Moreover, this study relies on travel self-report on actions that 
1 may happen in the future. Drawing strong conclusions based on travelers' plans for the future

2 may not reflect an eventual behavior.

3 The integration of the CCI and COVID-19 cases at multiple points in time added a

4 longitudinal element to the study to assess change in post-disaster camping trip plans, though

5 future researchers should track individual construal (i.e., time, space, social inclusion) over time

6 as well as assess both planned and enacted behaviors (e.g., planned camping trips compared to

7 actual camping trips). Considering that distance was positively related to post-disaster camping

8 trip plans, it will be fruitful for researchers to consider (1) characteristics of campgrounds (e.g.,

9 shared versus private bathrooms), (2) previous camping experiences and camper experience, (3)

10 accommodation type (i.e., owned versus rented), (4) transportation type (i.e., personal versus

11 shared), and (5) possible interaction effects between distance and COVID-19 scale. Such results

12 will help inform future iterations and applications of the CWD. Conducting longitudinal studies

13 will also allow future researchers to assess potential differences between perceived psychological

14 spatial distance and actual distance traveled.

15 The $\mathrm{R}^{2}$ changes in the models for COVID-19 cases and CCI are modest (see Table IV),

16 though the findings are impressive considering the variables used were state-level stimuli.

17 However, the study provides: (1) a framework (i.e., CWD) and empirical justification for

18 comparable mixed-methods future research and (2) guidance for future researchers to utilize

19 experimental designs to generate groups based on more granular climate experience (e.g.,

20 household or county-level) and more clearly define local restrictions (e.g., county-level

21 restrictions) to establish causality. To accommodate more robust experimental research designs,

22 it is important that researchers also collect higher resolution location data (e.g., household, zip-

23 code, county) from travelers to more accurately capture temporal, spatial, and social proximity to 
1 natural environment stimuli. Using higher resolution location data will also make it possible for

2 destination managers and authorities to geographically segment potential future travelers more

3 accurately.

4 5. Conclusion

COVID-19 represents a new yet salient non-meteorological/climatological disaster

6 influencing leisure travel decisions. Climate change continues to impact nature-based tourism-

7 especially camping - as a destination's resources consist of multiple weather variables that

8 tourists experience during visitation. Extending the Construal Level Theory (CLT), we introduce

9 the theoretical and empirical Camping-Weather-Disaster (CWD) framework to capture multiple

10 stimuli (i.e., CCI and COVID-19) also taking into consideration (1) traveler construal about a

11 disaster, (2) traveler psychological distance (time, space, social inclusion) from a disaster, and

12 (3) the scale of stimuli. Study findings highlight the salience of disaster scale, where greater

13 scale is inversely related to travel plans despite favorable or improving weather. Results also

14 indicate that leisure travelers who live where disaster scale is the greatest are willing to travel

15 further to camp. The theoretical development and empirical verification of the CWD highlight

16 the importance for destination managers and authorities to enhance understanding of

17 socioecological systems upon which their organizations rely. In turn, understanding can promote

18 organizational learning and help build organizational agency to take mitigating/adaptive actions

19 to address future natural conditions, disasters, and crises. 


\section{References}

2 Aliperti, G., Sandholz, S., Hagenlocher M., Rizzi, F., Frey, M., \& Garschagen, M. (2019). Tourism, crisis, disaster: An interdisciplinary approach. Annals of Tourism Research, 79, 102808.

Bansal, P., Kim, A., \& Wood, M.O. (2018). Hidden in plain sight. The importance of scale in organizations' attention to issues. Academy of Management Review, 43(2), 217-241.

Bansal, P., Grewatsch, S., \& Sharma, G. (2020). How COVID-19 informs business sustainability research: it's time for a systems perspective. Journal of Management Studies, https://doi.org/10.1111/joms.12669.

Becken, S., Mahon, R., Rennie, H., \& Shakeela, A. (2014). The tourism disaster vulnerability framework: an application to tourism in small island destinations. Natural Hazards, 71(1), 955-972.

Berger, L., Emmerling, J., \& Tavoni, M. (2017). Managing catastrophic climate risks under model uncertainty aversion. Management Science, 63, doi: https://doi.org/10.1287/mnsc.2015.2365

Bhaskara, G.I., \& Filimonau, V. (2021). The COVID-19 pandemic and organizational learning for disaster planning and management: A perspective of tourism businesses from a destination prone to consecutive disasters. Journal of Hospitality and Tourism Management, 46, 364-375.

Bowen, F.E., Bansal, P., \& Slawinski, N. (2018). Scale matters: The scale of environmental issues in corporate collective actions. Strategic Management Journal, 39(5), doi: https://doi.org/10.1002/smj.2764. 
1 Brugger, A. (2020). Understanding the psychological distance of climate change: The limitations

2 of the construal level theory and suggestions for alternative theoretical perspective.

3 Global Environmental Change, 60, 102023.

4 CCG (2019). 2019 North American camping report: 5-year trends. Sponsored by Kampgrounds of America. Retrieved at https://koa.com/north-american-camping-report/ amid COVID-19. Sponsored by Kampgrounds of America. https://koa.com/northamerican-camping-report/

9 CCG (2020b). North American camping and the effects of COVID-19. Sponsored by

11 CDC (2020). United States COVID-19 cases and deaths by state over time [dataset]. Retrieved at https://data.cdc.gov/Case-Surveillance/United-States-COVID-19-Cases-and-Deaths-by-

14 Chang, H., Zhang, L., \& Xie, G-X. (2015). Message framing in green advertising: The effect of construal level and consumer environmental concern. International Journal of Advertising, 34, 158-176.

17 Chang, H., \& Sokol, D.D. (2020). How incumbents respond to competition from innovative disruptors in the sharing economy-The impact of Airbnb on hotel performance. Strategic Management Journal, https://doi.org/10.1002/smj.3201. https://doi.org/10.1016/j.tourman.2018.02.013 
1 Craig, C.A. (2019). The Weather-Proximity-Cognition (WPC) framework: A camping, weather, and climate change case. Tourism Management, 75, 340-352.

3 Craig, C.A., Feng, S., \& Gilbertz, S. (2019). Water crisis, drought, and climate change in the 4 southeast United States. Land Use Policy, 88, 104110.

5 Craig, C.A., Allen, M.W., Feng, S., \& Spialek, M. (2020). Exploring the impact of resident proximity to wildfires in the northern Rocky Mountains: Perceptions of climate change risks, drought, and policy. International Journal of Disaster Risk Reduction, 44, 101420. DOI: https://doi.org/10.1016/j.ijdrr.2019.101420

Craig, C.A. (2021). Camping, glamping, and coronavirus in the United States. Annals of Tourism Research, 89, 103071. DOI: https://doi.org/10.1016/j.annals.2020.103071

Craig, C.A., \& Karabas, I. (2021). Glamping after the coronavirus pandemic. Tourism and Hospitality Research, 21(2), 251-256. DOI: 10.1177/1467358421993864

Craig, C.A., Ma, S., \& Karabas, I. (2021). COVID-19, camping, and Construal Level Theory. Current Issues in Tourism, DOI: 10.1080/13683500.2021.1895730Dogan, M., \& Erdogan, B.A. (2020). Effects of congruence between individuals' and hotel commercials' construal levels on purchase intentions. Journal of Hospitality Marketing \& Management, 29(8), 987-1007).

Dolnicar, S., \& Zare, S. (2020, March 18). COVID-19 and Airbnb - Disrupting the disruptor. Annals of Tourism Research, DOI: doi.org/10.1016/j.annals.2020.102961

Faulkner, B. (2001). Toward a framework of tourism disaster management. Tourism Management, 22(2), 135-147. 
1 Floyd, M.F., Gibson, H., Pennington-Gray, L., \& Thapa, B. (2008). The effect of risk perceptions on intentions to travel in the aftermath of September 11, 2001. Journal of Travel \& Tourism Marketing, 15(2-3), $19-38$.

4 Freedman, A. (2020, September 6). California endures record-setting 'kiln-like' heat as fire rages, causing injuries. The Washington Post. https://www.washingtonpost.com/weather/2020/09/06/california-wildfires-heat-wave/

Glaser, T., Lewandowski, J., \& Dusing, J. (2015). The long and winding road to uncertainty: The link between spatial distance and feelings of uncertainty. PLOS ONE, 10(3), e0119108. Doi:10.1371/journal.pone.0119108

Gossling, S., Scott, D., \& Hall, M. (2020). Pandemics, tourism and global change: A rapid assessment of COVID-19. Journal of Sustainable Tourism, DOI:10.1080/09669582.2020.1758708

Granvorka, C., \& Strobl, E. (2013). The impact of hurricane strikes on tourist arrivals in the Caribbean. Tourism Economics, 19(6), 1401-1409.

Hein, W., Wilson, C., Lee, B., Rajapaksa, D., de Moel, H. Athrukorala, W., \& Managi, S. (2019). Climate change and natural disasters: Government mitigation activities and public property damage response. Land Use Policy, 82, 436-44.

Hewer, M. J., Scott, D. J., Gough, W. A. (2017). Differential temperature preferences and thresholds among summer campers in Ontario's southern provincial parks: A Canadian case study in tourism climatology. Theoretical and Applied Climatology, 133, 1163 1173. 
1 Johns Hopkins (2020). COVID-19 dashboard by the Center for Systems Science and Engineering

2 (CSSE) at Johns Hopkins University (JHU). Retrieved from

3 https://coronavirus.jhu.edu/map.html

4 Karl, T.R., \& Koss, W.J. (1984). Regional and national monthly, seasonal, and annual

temperature weighted by area, 1985-1983. Historical Climatology Series 4-3. National Climatic Data Center: Asheville, NC.

7 Kim, H.S., \& Lee, J.C. (2020). Effect of COVID-19 preference for private dining facilities in restaurants. Journal of Hospitality and Tourism Management, 45, 67-70.

9 Kim, J., Kim, P.B., Kim, J.E., \& Magnini, V.P. (2016). Application of construal-level theory to promotional strategies in the hotel industry. Journal of Travel Research, 55(3), 340-352.

11 King, J.E. (2008). Binary logistic regression. In J.W. Osborne (Ed), Best Practices in Quantitative Methods (pp. 358-384). SAGE Publications.

13 Liberman, N., \& Trope, Y. (1998). The role of feasibility and desirability in near and distant future decisions. A test of temporal construal theory. Journal of Personality and Social Psychology, 75(1), 5-18.

16 Liberman, N., \& Trope, Y. (2008). The psychology of transcending the here and now. Science, 322(5906), 1201-1205.

Ma, S., Craig, C.A., \& Feng, S. (2020). The Camping Climate Index (CCI): The development,

Ma, S., Craig, C.A., \& Feng, S. (2021). Camping climate resources: The Camping Climate Index (CCI) in the United States. Current Issues in Tourism, doi: 
1 Ma, S., Craig, C.A., \& Feng, S. (2021). Climate resources at United States National Parks: A tourism climate index approach. Tourism Recreation Research, DOI: $10.1080 / 02508281.2021 .1946652$

4 Mahn, C., Scarles, C., Edwards, J., \& Tribe, J. (2020). Personalising disaster: Community storytelling and sharing in New Orleans post-Katrina tourism. Tourist Studies, 21(2), 156-177.

Matthews, L., Scott, D. \& Andrey, J. (2019). Development of a data-driven weather index for beach parks tourism. International Journal of Biometeorology, doi: https://doi.org/10.1007/s00484-019-01799-7.

10 Messer, L.C. (2008). Natural experiment. In S. Boslaugh (Ed), Encyclopedia of Epidemiology (pp. 720-721). Sage Publications.

12 Mieczkowski, Z. (1985). The tourism climatic index: A method of evaluating world climates for tourism. The Canadian Geographer, 29(3), 220-233. https://doi.org/10.1111/j.15410064.1985.tb00365.x

15 Mildenberger, M., Lubell, M., \& Hummel, M. (2019). Personalized risk messaging can reduce

17 Miller, H. (2020, April 30). Reopening America: A state-by-state breakdown of the status of coronavirus restrictions. CNBC. Retrieved 9/5/2020 from https://www.cnbc.com/2020/04/30/coronavirus-states-lifting-stay-at-home-ordersreopening-businesses.html. climate concerns. Global Environmental Change, 55, 15-24. 
1 Oster, A. M., Kang, G. A., Cha, A. E., Bersovsky, V., Rose, C. E., Rainisch, G., Porter, L., ... , Villanueva, J. (2020). Trends in number of distribution of COVID-19 Hotspot Counties United State, March 8 - July 15, 2020. CDC. Morbidity and Mortality Weekly Report, 69(33), 1127-1132.

Pancevski, B., Colchester, M, \& Kostov, N. (2021, February 16). COVID-19 variants outpace Europe's slow vaccine rollout. The Wall Street Journal. Available at: https://www.wsj.com/articles/covid-19-variants-outpace-europes-slow-vaccine-rollout$11613481282 ? \mathrm{mod}=$ article_inline $($ accessed March 18, 2021).

Rice, W.L., Newman, P., \& Pan, B. (2019). Forecasting campground demand in US national parks. Annals of Tourism Research, 75, 424-438.

Rice, W.L., Mateer, T.J., Reigner, N., Newman, P., Lawhon, B., \& Taff, B.D. (2020). Changes in recreational behaviors of outdoor enthusiasts during the COVID-19 pandemic: Analysis across urban and rural communities. Journal of Urban Ecology, 6(1), https://doi.org/10.1093/jue/juaa020.

Reidmiller, D.R., Avery, C.W., Easterling, D.R., Kunkel, K.E., Lewis, K.L.M., Maycock, T.K. \& Stewart, B.C. (Eds) (2018). Impacts, risks, and adaptation in the United States: Fourth National Climate Assessment. U.S. Global Change Research Program: Washington, D.C. doi:10.7930/NCA4.2018

Ritchie, B.W. (2004). Chaos, crises, and disasters: A strategic approach to crisis management in the tourism industry. Tourism Management, 25, 669-683.

Ritchie, B.W., \& Jiang, Y. (2019). A review of tourism risk, crisis and disaster management: Launching the annals of tourism research curated collection on tourism risk, crisis and disaster management. Annals of Tourism Research, 69, 102812. 
1 Robbie, D. (2008). Touring Katrina: Authentic identities and disaster tourism in New Orleans. Journal of Heritage Tourism, 3(4), 257-266.

3 Sohrabizadeh, S., Yousefian, S., Bahramzadeh, A., Vaziri, M.H. (2021). A systematic review of

4 health sector responses to the coincidence of disasters and COVID-19. BMC Public Health, 21, 709. https://doi.org/10.1186/s12889-021-10806-9

6 Rutty, M., \& Scott, D. (2010). An inter-comparison of the Holiday Climate Index (HCI) and the Tourism Climate Index (TCI) in Europe. Atmosphere, 7(6). doi: 10.3990/atmos7060080

8 Sear, R.F., Velaszuez, N., Leahy, R., Restrepo, N.J., Oud, S.E., Gabriel, N., Lupu, Y., \& Johnson, N.F. (2020). Quantifying COVID-19 content in the online health opinion war using machine learning. IEEE Access, 8, 91,886-91,893. DOI:

Sharuf, I.M., Ahmadun, F., \& Said, A.M. (2003). A review of disaster and crisis. Disaster Prevention and Management, 12(1), 24-32.

14 Spialek, M., Allen, M. W., \& Craig, C. A. (2021). The relationship between the disaster

STR and Tourism Economics (2020, June 26). U.S. Hotel Demand Not Expected to Fully

21 Tashman, P., \& Rivera, J. (2016). Ecological uncertainty, adaptation, and mitigation in the U.S. Recover until 2023. https://str.com/press-release/us-hotel-demand-not-expected-fullyski resort industry: Managing resource dependence and institutional pressures. Strategic Management Journal, 37, 1507-1525. 
1 Trope, Y., \& Liberman, N. (2010). Construal-level theory of psychological distance. Psychological Review, 117(2), 440-463.

3 United Nations World Tourism Organization (UNWTO; 2019). International Tourism

$4 \quad$ Highlights, 2019 Edition. DOI: 10.18111/9789284421152

5 United Nations World Tourism Organization (UNWTO; 2020). Impact assessment of the

6 COVID-19 outbreak on international tourism. https://www.unwto.org/impact-

7 assessment-of-the-covid-19-outbreak-on-international-tourism

8 van Lent, L. G. G., Sungur, H., Kunneman, F. A., de Velde, B., \& Das, E. (2017). Too far to

9 care? Measuring public attention and fear for Ebola using Twitter. Journal of Medical

10 Internet Research, 19(6), e193. Doi: 10.2196/jmir.7219

11 Wilkins, E., de Urioste-Stone, S., Weiskittel, A., \& Gabe, T. (2017). Effects of weather on tourism spending: Implications for future trends under climate change. Journal of Travel

14 World Health Organization (WHO; 2020). Vaccines and immunization: What is vaccination? https://www.who.int/news-room/q-a-detail/vaccines-and-immunization-what-is-

17 World Health Organization (WHO; 2021a). Coronavirus. https://www.who.int/healthtopics/coronavirus

19 World Health Organization (WHO; 2021b). Coronavirus disease (COVID-19) advice for the public. https://www.who.int/emergencies/diseases/novel-coronavirus-2019/advice-forpublic

22 Yeh, S. (2020). Tourism recovery strategy against COVID-19 pandemic. Tourism Recreation Research, 46(2), 188-194. 
1 Yu, J., Lee, K., \& Hyun, S.S. (2021). Understanding the influence of the perceived risk of the coronavirus disaster (COVID-19) on the post-traumatic stress disorder and revisit intention of hotel guests. Journal of Hospitality and Tourism Management, 46, 327-335. 


\section{$1 \quad$ Figures and Tables}

2 Figure 1. Camping-Weather-Disaster (CWD) framework

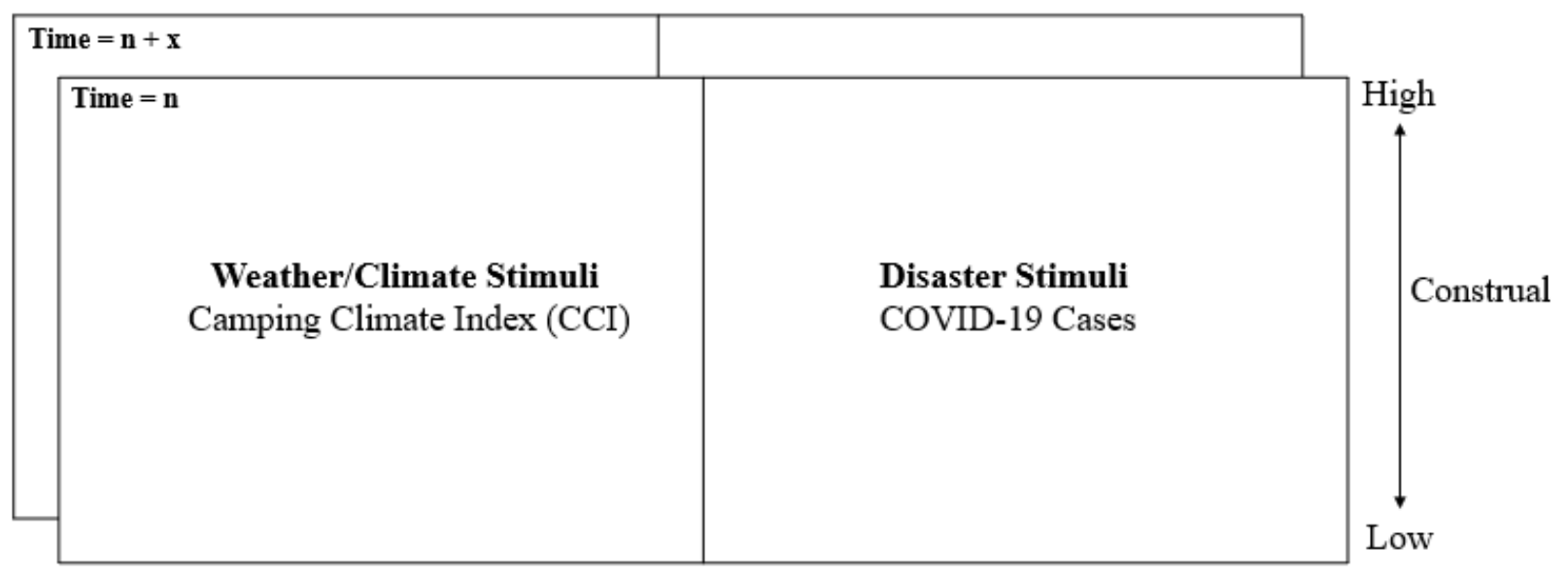

Time, Space, Social Inclusion, Scale

3

$\stackrel{\text { Distant/Large } \quad \text { Proximate/Small }}{\longrightarrow}$

4 Table I. CCI weather variables

\begin{tabular}{|l|l|l|l|l|}
\hline $\begin{array}{l}\text { Sub-index } \\
\text { variable }\end{array}$ & Initials & $\begin{array}{l}\text { Climate } \\
\text { Resource }\end{array}$ & Units & Climate variable required \\
\hline $\begin{array}{l}\text { Thermal } \\
\text { Comfort }\end{array}$ & TC & Thermal & $\begin{array}{l}\text { Reported as } \\
{ }^{\circ} \mathrm{C}\end{array}$ & $\begin{array}{l}\text { Mean temperature }\left({ }^{\circ} \mathrm{C}\right) \\
\text { Mean dew point temperature } \\
\left({ }^{\circ} \mathrm{C}\right)\end{array}$ \\
\hline Temperature & $\begin{array}{l}\text { TMIN, } \\
\text { TMAX }\end{array}$ & Thermal & ${ }^{\circ} \mathrm{C}$ & $\begin{array}{l}\text { Minimum temperature and } \\
\text { maximum temperature }\left({ }^{\circ} \mathrm{C}\right)\end{array}$ \\
\hline $\begin{array}{l}\text { Sunshine } \\
\text { hours }\end{array}$ & $\mathrm{S}$ & Aesthetic & Hours $(\mathrm{hr})$ & $\begin{array}{l}\text { Solar radiation }\left(\mathrm{w} / \mathrm{m}^{2}\right) \\
\text { Location coordinates }\end{array}$ \\
\hline $\begin{array}{l}\text { Precipitation } \\
\text { Windspeed }\end{array}$ & $\mathrm{P}$ & Physical & $\begin{array}{l}\text { Millimeters } \\
(\mathrm{mm})\end{array}$ & Precipitation $(\mathrm{mm})$ \\
\hline
\end{tabular}


Table II. Sample characteristics

\begin{tabular}{|c|c|}
\hline \multicolumn{2}{|c|}{ Northeast climate region $(n=442)$} \\
\hline Age & Average $=40.31 ;$ range 18 to 102 \\
\hline Income & $\begin{array}{l}\text { 9.7\% under } \$ 25,000,17.0 \% \$ 25,000-\$ 50,000,14.0 \% \$ 50,000-\$ 75,000,14.7 \% \$ 75,000- \\
\$ 100,000,23.3 \% \$ 100,000-\$ 150,000,12.2 \% \$ 150,000-\$ 200,000,9.0 \% \text { over } \$ 200,000\end{array}$ \\
\hline Ethnicity & $81.7 \%$ Caucasian/White, $18.3 \%$ other ethnic background \\
\hline Gender & $56.3 \%$ male, $43.4 \%$ female, $.2 \%$ other \\
\hline Employment & $\begin{array}{l}67.0 \% \text { full-time, } 11.1 \% \text { part-time, } 6.6 \% \text { student, } 6.6 \% \text { retired, } 2.7 \% \text { home maker/stay at } \\
\text { home parent, } 5.6 \% \text { unemployed or furloughed because of COVID- } 19, .5 \% \text { unemployed or } \\
\text { furloughed not related to COVID }\end{array}$ \\
\hline Time & $\begin{array}{l}19.5 \% \text { now, } 13.6 \% \text { within next } 1 \text { or } 2 \text { weeks, } 13.1 \% \text { within month, } 17.2 \% 1-2 \text { months, } \\
14.0 \% \text { 3-4 months, } 11.8 \% 5-6 \text { months, } 10.9 \% \text { more than } 6 \text { months }\end{array}$ \\
\hline Space & $\begin{array}{l}\text { 9.3\% within } 25 \text { miles, } 22.2 \% 26-50 \text { miles, } 22.4 \% 51-100 \text { miles, } 15.6 \% 101-150 \text { miles, } \\
5.4 \% 151-200 \text { miles, } 6.3 \% 201-300 \text { miles, } 8.8 \% \text { more than } 300 \text { miles, } 10.0 \% \text { no maximum } \\
\text { distance }\end{array}$ \\
\hline Social Inclusion & $34.8 \%$ (1) severe, $38.9 \%$ (2), $14.3 \%$ (3), $8.4 \%$ (3), $3.6 \%$ (5) none \\
\hline \multicolumn{2}{|c|}{ All other climate regions $(n=1372)$} \\
\hline Age & Average $=39.08 ;$ range 18 to 102 \\
\hline Income & $\begin{array}{l}12.0 \% \text { under } \$ 25,000,23.3 \% \$ 25,000-\$ 50,000,16.0 \% \$ 50,000-\$ 75,000,14.7 \% \$ 75,000 \\
-\$ 100,000,18.5 \% \$ 100,000-\$ 150,000,7.8 \% \$ 150,000-\$ 200,000,8.7 \% \text { over } \$ 200,000\end{array}$ \\
\hline Ethnicity & 73.0\% Caucasian/White, $27.0 \%$ other ethnic background \\
\hline Gender & $46.9 \%$ male, $52.5 \%$ female, $.7 \%$ other \\
\hline Employment & $\begin{array}{l}60.4 \% \text { full-time, } 12.6 \% \text { part-time, } 7.0 \% \text { student, } 7.0 \% \text { retired, } 5.4 \% \text { home maker/stay at } \\
\text { home parent, } 5.9 \% \text { unemployed or furloughed because of COVID- } 19,1.7 \% \text { unemployed or } \\
\text { furloughed not related to COVID }\end{array}$ \\
\hline Time & $\begin{array}{l}21.7 \% \text { now, } 15.9 \% \text { within next } 1 \text { or } 2 \text { weeks, } 12.5 \% \text { within month, } 16.0 \% 1-2 \text { months, } \\
14.2 \% 3-4 \text { months, } 10.3 \% 5-6 \text { months, } 9.3 \% \text { more than } 6 \text { months }\end{array}$ \\
\hline Space & $\begin{array}{l}9.3 \% \text { within } 25 \text { miles, } 20.6 \% 26-50 \text { miles, } 19.5 \% 51-100 \text { miles, } 14.6 \% 101-150 \text { miles, } \\
7.7 \% 151-200 \text { miles, } 10.0 \% 201-300 \text { miles, } 9.6 \% \text { more than } 300 \text { miles, } 8.8 \% \text { no maximum } \\
\text { distance }\end{array}$ \\
\hline Social Inclusion & $23.1 \%$ (1) severe, $33.5 \%(2), 25.7 \%(3), 13.3 \%$ (4) and $4.4 \%(5)$ none \\
\hline
\end{tabular}

3 *Note. "Uncertain" responses were removed to prepare the binary logistic regression for time, space, and social 4 inclusion

7 Figure 2. Spring monthly CCI scores 2020 


\section{March}

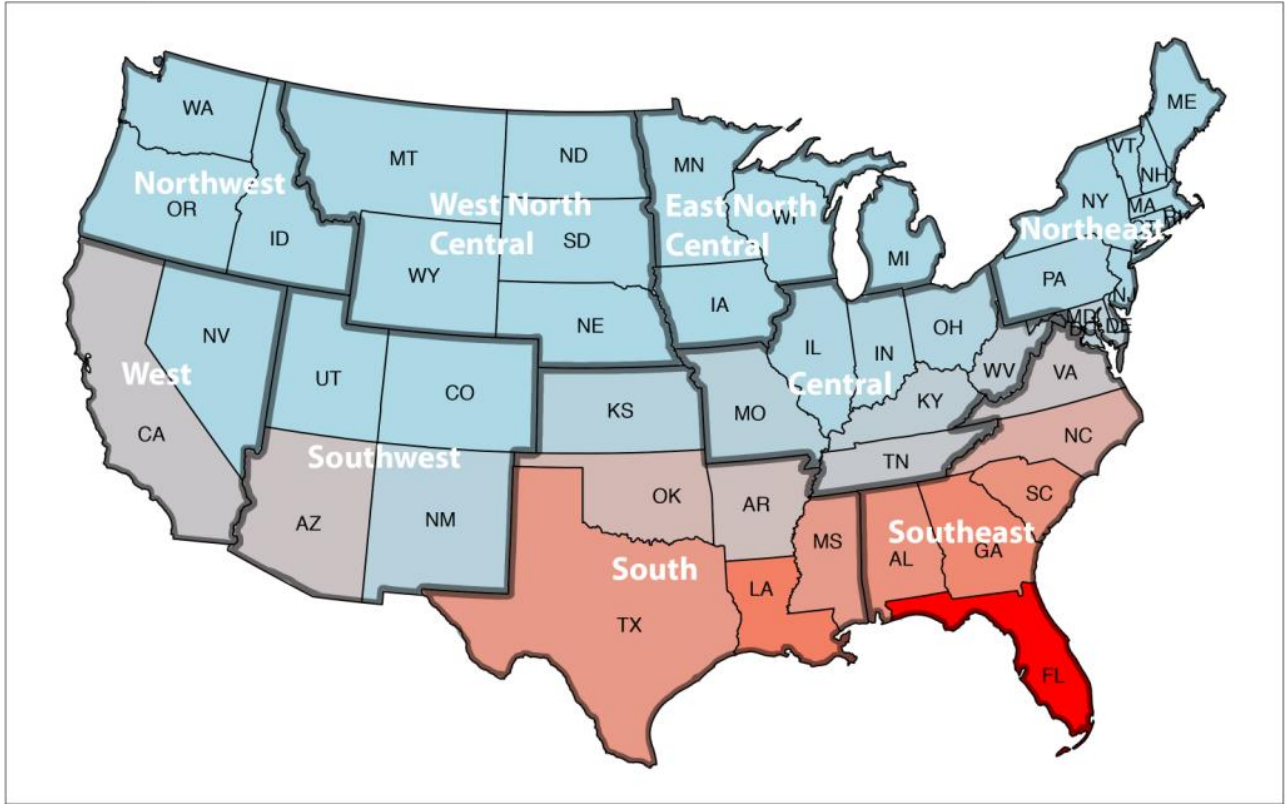

\section{April}

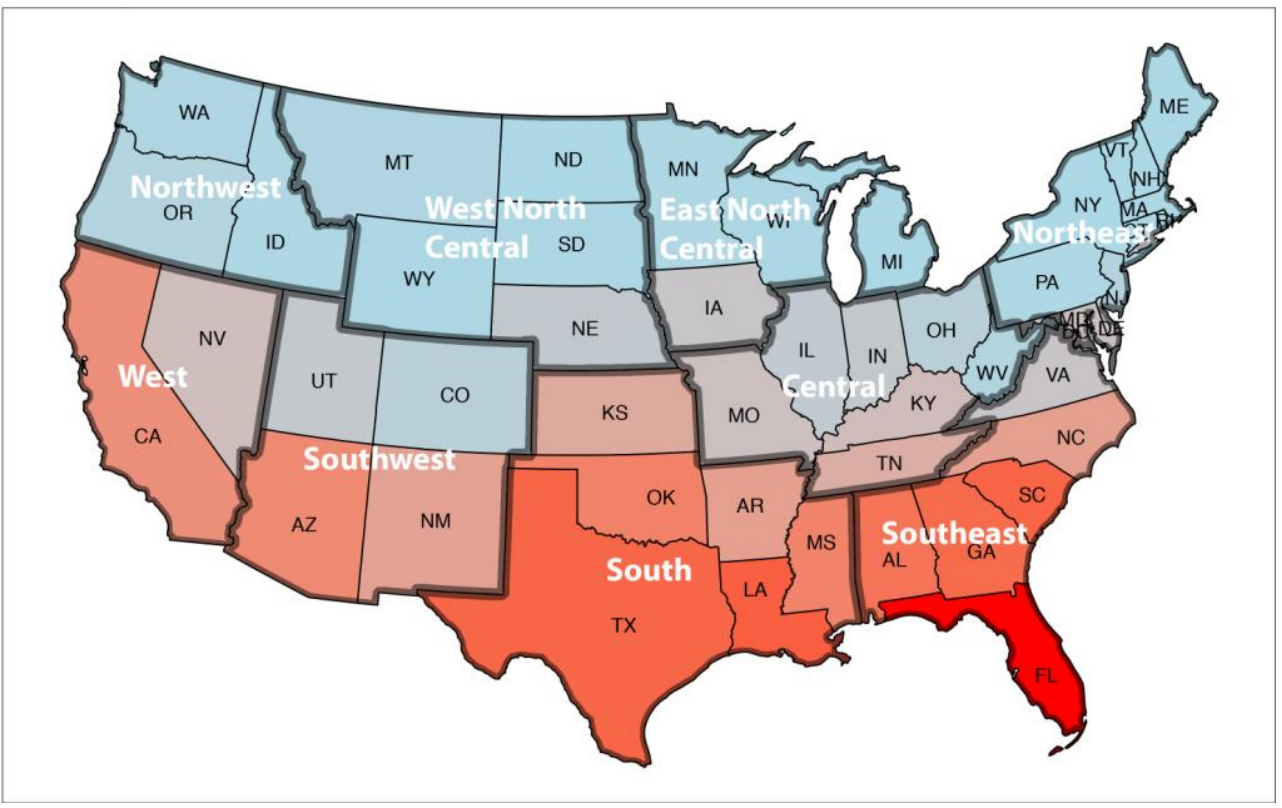


May

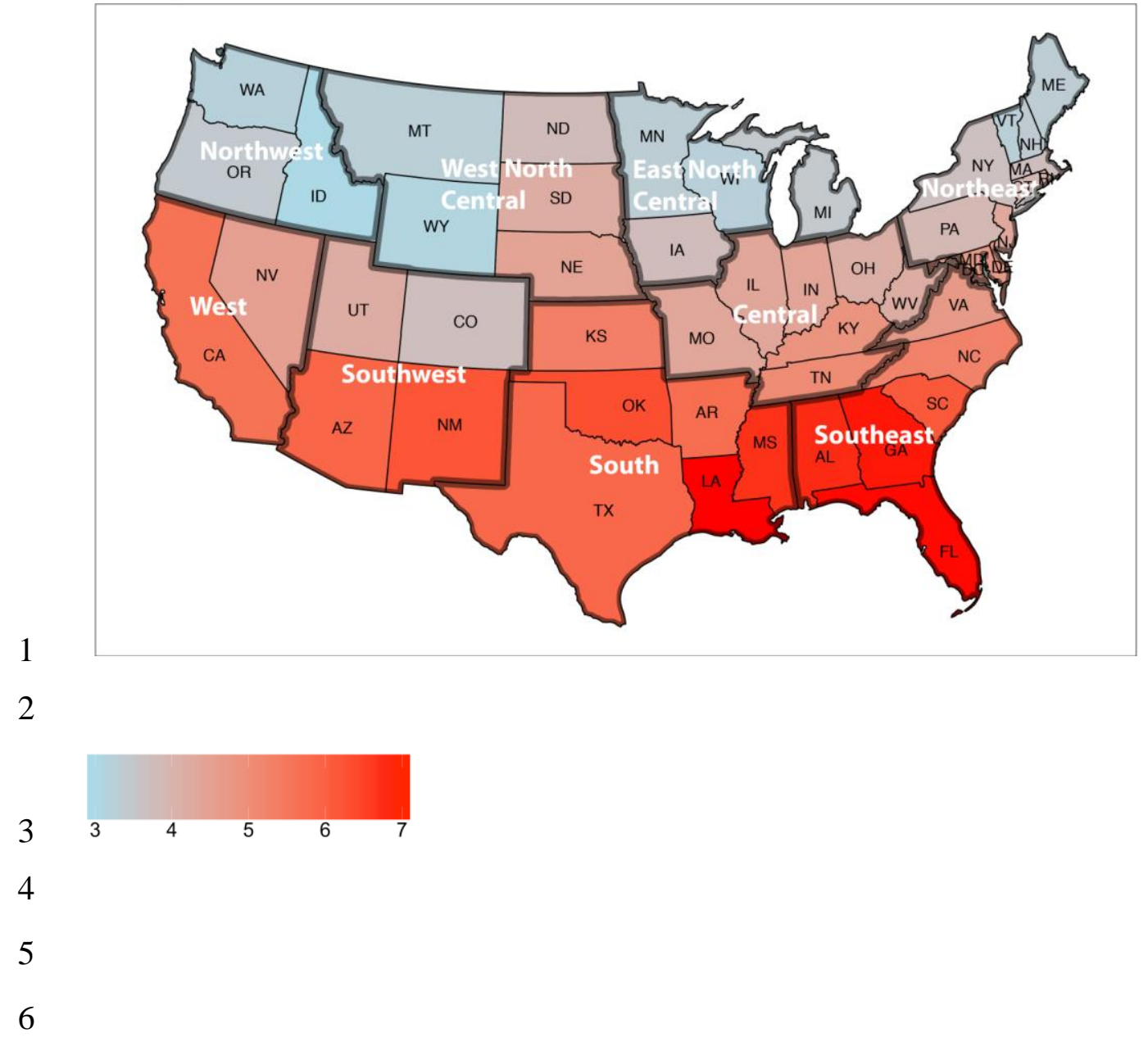


1 Table III. Descriptives for psychological distance variables

\begin{tabular}{|c|c|c|c|c|c|c|c|}
\hline \multicolumn{8}{|c|}{ Northeast climate region } \\
\hline & $\mathrm{N}$ & $\mathrm{M}$ & SD & Skewness & SE & Kurtosis & SE \\
\hline Time & 442 & 3.710 & 1.985 & 0.120 & 0.116 & -1.188 & 0.232 \\
\hline Space & 442 & 3.900 & 2.154 & 0.627 & 0.116 & -0.792 & 0.232 \\
\hline Social & 442 & 2.070 & 1.072 & 0.980 & 0.116 & 0.358 & 0.232 \\
\hline \multicolumn{8}{|c|}{ All other regions } \\
\hline Time & 1372 & 3.530 & 1.973 & 0.232 & 0.066 & -1.164 & 0.132 \\
\hline Space & 1372 & 4.030 & 2.146 & 0.436 & 0.066 & -0.998 & 0.132 \\
\hline Social & 1372 & 2.420 & 1.112 & 0.458 & 0.066 & -0.548 & 0.132 \\
\hline
\end{tabular}

3 Table IV. Binary logistic regression for post-disaster camping trip plans

\begin{tabular}{|c|c|c|c|c|c|c|c|c|c|c|c|}
\hline \multicolumn{6}{|c|}{ Northeast climate region $(n=442)$} & \multicolumn{6}{|c|}{ All other climate regions $(n=1,372)$} \\
\hline \multicolumn{6}{|c|}{ Block $1(R 2=.160, p=.000)$} & \multicolumn{6}{|c|}{ Block $1(R 2=.142, p=.000)$} \\
\hline Variable & $B$ & S.E. & $d f$ & Sig. & $\operatorname{Exp}(B)$ & Variable & $B$ & S.E. & $d f$ & Sig. & $\operatorname{Exp}(B)$ \\
\hline Age & -.023 & .007 & 1 & .001 & .977 & Age & -.014 & .004 & 1 & .000 & .986 \\
\hline Income & .228 & .064 & 1 & .000 & 1.256 & Income & .168 & .034 & 1 & .000 & 1.182 \\
\hline Gender & .752 & .216 & 1 & .000 & 2.122 & Gender & .952 & .12 & 1 & .000 & 2.592 \\
\hline Ethnicity & -.958 & .295 & 1 & .001 & .384 & Ethnicity & -.63 & .135 & 1 & .000 & .533 \\
\hline Laid-Off & .413 & .455 & 1 & .364 & 1.512 & Laid-Off & .521 & .253 & 1 & .039 & 1.683 \\
\hline Constant & .404 & .581 & 1 & .486 & 1.498 & Constant & -.348 & .304 & 1 & .253 & .706 \\
\hline \multicolumn{6}{|c|}{ Block $2(R 2=.203, \Delta=.043, p=.001)$} & \multicolumn{6}{|c|}{ Block $2(R 2=.162, \Delta=.020, p=.000)$} \\
\hline Age & -.023 & .007 & 1 & .002 & .977 & Age & -.013 & .004 & 1 & .001 & .987 \\
\hline Income & .193 & .065 & 1 & .003 & 1.212 & Income & .155 & .034 & 1 & .000 & 1.167 \\
\hline Gender & .709 & .221 & 1 & .001 & 2.032 & Gender & .887 & .122 & 1 & .000 & 2.428 \\
\hline Ethnicity & -.932 & .302 & 1 & .002 & .394 & Ethnicity & -.576 & .136 & 1 & .000 & .562 \\
\hline Laid-Off & .249 & .47 & 1 & .596 & 1.283 & Laid-Off & .468 & .256 & 1 & .067 & 1.597 \\
\hline March CCI & -.844 & 1.275 & 1 & .508 & .43 & March CCI & .191 & .085 & 1 & .025 & 1.211 \\
\hline April CCI & .45 & .22 & 1 & .041 & 1.568 & April CCI & -.062 & .08 & 1 & .439 & .94 \\
\hline May CCI & -.902 & .231 & 1 & .000 & .406 & May CCI & .123 & .081 & 1 & .131 & 1.131 \\
\hline Constant & 7.079 & 5.153 & 1 & .17 & 1186.32 & Constant & -1.746 & .464 & 1 & .000 & .174 \\
\hline
\end{tabular}




\section{Table IV cont.}

\begin{tabular}{|c|c|c|c|c|c|c|c|c|c|c|c|}
\hline \multicolumn{6}{|c|}{ Northeast climate region $(n=442)$} & \multicolumn{6}{|c|}{ All other climate regions $(n=1,372)$} \\
\hline \multicolumn{6}{|c|}{ Block $3(R 2=.272, \Delta=.069, p=.00)$} & \multicolumn{6}{|c|}{ Block $3(R 2=.164, \Delta=.002, p=.420)$} \\
\hline Variable & $B$ & S.E. & $d f$ & Sig. & $\operatorname{Exp}(B)$ & Variable & $B$ & S.E. & $d f$ & Sig. & $\operatorname{Exp}(B)$ \\
\hline Age & -.02 & .007 & 1 & .008 & .98 & Age & -.013 & .004 & 1 & .001 & .987 \\
\hline Income & .116 & .07 & 1 & .095 & 1.123 & Income & .148 & .035 & 1 & .000 & 1.159 \\
\hline Gender & .458 & .234 & 1 & .05 & 1.582 & Gender & .865 & .123 & 1 & .000 & 2.375 \\
\hline Ethnicity & -.99 & .303 & 1 & .001 & .372 & Ethnicity & -.563 & .136 & 1 & .000 & .57 \\
\hline Laid-Off & .161 & .468 & 1 & .73 & 1.175 & Laid-Off & .467 & .256 & 1 & .068 & 1.596 \\
\hline March CCI & -1.009 & 1.33 & 1 & .448 & .365 & March CCI & .164 & .091 & 1 & .071 & 1.179 \\
\hline April CCI & .324 & .226 & 1 & .152 & 1.382 & April CCI & -.036 & .092 & 1 & .696 & .965 \\
\hline May CCI & .046 & .296 & 1 & .877 & 1.047 & May CCI & .093 & .088 & 1 & .288 & 1.098 \\
\hline April 1 Cases & .101 & .034 & 1 & .003 & 1.107 & April 1 Cases & .015 & .064 & 1 & .808 & 1.016 \\
\hline April 30 Cases & -.025 & .01 & 1 & .016 & .975 & April 30 Cases & .002 & .011 & 1 & .845 & 1.002 \\
\hline Constant & 3.526 & 5.271 & 1 & .504 & 33.999 & Constant & -1.675 & .469 & 1 & .000 & .187 \\
\hline \multicolumn{6}{|c|}{ Block $4(R 2=.316, \Delta=.044, p=.000)$} & \multicolumn{6}{|c|}{ Block $4(R 2=.209, \Delta=.045, p=.000)$} \\
\hline Age & -.018 & .008 & 1 & .016 & .982 & Age & -.01 & .004 & 1 & .009 & .99 \\
\hline Income & .166 & .073 & 1 & .024 & 1.18 & Income & .174 & .036 & 1 & .000 & 1.19 \\
\hline Gender & .388 & .241 & 1 & .107 & 1.474 & Gender & .785 & .126 & 1 & .000 & 2.193 \\
\hline Ethnicity & -1.124 & .315 & 1 & .000 & .325 & Ethnicity & -.665 & .14 & 1 & .000 & .514 \\
\hline Laid-Off & .053 & .481 & 1 & .912 & 1.054 & Laid-Off & .353 & .256 & 1 & .168 & 1.423 \\
\hline March CCI & -.991 & 1.424 & 1 & .486 & .371 & March CCI & .158 & .093 & 1 & .089 & 1.171 \\
\hline April CCI & .345 & .232 & 1 & .138 & 1.412 & April CCI & -.002 & .094 & 1 & .986 & .998 \\
\hline May CCI & .121 & .305 & 1 & .691 & 1.129 & May CCI & .086 & .09 & 1 & .341 & 1.09 \\
\hline April 1 Cases & .1 & .036 & 1 & .005 & 1.106 & April 1 Cases & .032 & .065 & 1 & .625 & 1.032 \\
\hline April 30 Cases & -.025 & .011 & 1 & .021 & .975 & April 30 Cases & 0 & .012 & 1 & .985 & 1 \\
\hline Time & -.193 & .06 & 1 & .001 & .824 & Time & -.205 & .031 & 1 & .000 & 0.815 \\
\hline Space & .192 & .111 & 1 & .083 & 1.211 & Space & .05 & .055 & 1 & .36 & 1.052 \\
\hline $\begin{array}{l}\text { Social } \\
\text { Inclusion }\end{array}$ & -.099 & .048 & 1 & .04 & .905 & $\begin{array}{l}\text { Social } \\
\text { Inclusion }\end{array}$ & -.068 & .025 & 1 & .008 & .934 \\
\hline Constant & 3.669 & 5.666 & 1 & .517 & 39.232 & Constant & -.912 & .527 & 1 & .083 & .402 \\
\hline
\end{tabular}

